\title{
Generation of Eosinophils from Unselected Bone Marrow Progenitors: Wild-Type, TLR- and Eosinophil-Deficient Mice
}

\author{
Kimberly D. Dyer, Caroline M. Percopo and Helene F. Rosenberg* \\ Laboratory of Allergic Diseases, National Institute of Allergy and Infectious Diseases, National Institutes of Health, \\ Bethesda, Maryland 20892, USA
}

\begin{abstract}
We have recently devised a culture method that generates large numbers of eosinophils at high purity from unselected BALB/c mouse bone marrow progenitors [Dyer et al., 2008. J. Immunol. 181: 4004-9]. Here we present the extended scope of this approach, as we have used this method successfully to generate eosinophil cultures of virtually $100 \%$ purity from bone marrow from C57BL/6 mice, and from TLR2, TLR3, TLR7 and TLR9-gene-deleted mouse strains on the C57BL/6 background. Both wild-type and TLR3 gene-deleted bone marrow eosinophils (bmEos) are functional, releasing peroxidase in response to the secretogogue, platelet activating factor. We have also used this method to re-evaluate production of eosinophils in bone marrow cultures from $\triangle$ dblGATA mice, a strain that is eosinophildeficient in vivo. Interestingly, bmEos can be detected in the $\Delta$ dblGATA cultures (5\% of total cells at day 10$)$, although $\sim 80$-fold fewer bmEos are detected in $\triangle$ dblGATA than in parallel wild-type (BALB/c) bone marrow cultures. Overall, we find that generation of large numbers of eosinophils at high purity from unselected bone marrow progenitors proceeds efficiently in a variety of wild-type and gene-deleted strains, and as such this approach shows promise as a universal method for the study of eosinophil structure and function (199 words).
\end{abstract}

Keywords: Cytokines, interleukin-5, toll-like receptors, mouse, hematopoiesis.

\section{INTRODUCTION}

Eosinophils are granulocytic leukocytes that develop from pluripotent bone marrow progenitors in response to Th2 cytokine stimulation, most notably in response to elevated levels of interleukin-5 (reviewed in [1,2]). Although eosinophils are readily recognized by their distinct morphology, the biological role and functions of these cells remain uncertain and controversial. For example, although eosinophilia is a prominent component of the host response to helminthic parasite infection, the presumed role of eosinophils in anti-parasite host defense is not at all clear [3]; in fact, Fabre and colleagues [4] recently presented data suggesting that eosinophils serve to promote parasite, rather than host survival in a chronic infection model. Likewise, consensus opinion holds that eosinophils play a prominent role in pathogenesis of allergic asthma, yet large-scale clinical studies lead to conflicting conclusions [5-7].

In order to explore eosinophil development, and ultimately the function of individual genes and geneproducts within eosinophils, we developed a culture system which permits us to generate large numbers of eosinophils at high purity $(>95 \%)$ from unselected BALB/c bone marrow progenitors [8]. We found that $\mathrm{BALB} / \mathrm{c}$ bone marrowderived eosinophils (bmEos) expressed relevant transcripts and lineage-specific cell surface proteins and underwent chemotaxis in response to eotaxin-1. As only wild-type $\mathrm{BALB} / \mathrm{c}$ mice were evaluated in this first study, it was

*Address correspondence to this author at the Laboratory of Allergic Diseases, National Institute of Allergy and Infectious Diseases, National Institutes of Health, Bethesda, Maryland 20892, USA;

E-mail: hrosenberg@niaid.nih.gov important to determine whether our findings were unique to this one strain of mice, or whether this method might be applied more universally.

Here, we explore the potential of this method as a means to generate functional bmEos from the $\mathrm{C} 57 \mathrm{BL} / 6$ mice, as well as from bone marrow cells from specific gene-deleted mice on the C57BL/6 background. We also use this improved culture system to revisit our earlier findings [9], comparing the production of bmEos ex vivo from wild-type and eosinophil-deficient $\triangle$ dblGATA mice.

\section{MATERIALS AND METHODOLOGY}

Mice. Six to eight-week old wild-type BALB/c and C57BL/6 mice were purchased from Taconic Farms (Rockville, MD). Eosinophil-deficient $\triangle$ dblGATA mice on the BALB/c background [10] were bred and maintained on site. TLR2, TLR7, and TLR9 gene-deleted mice (C57BL/6 background) [11-13] are used with written permission of Dr. Shizuo Akira and were graciously provided by Dr. Rachel Caspi (NEI/NIH) and Dr. Jennifer Wang (U. Mass. Medical). TLR3 gene-deleted mice [14] were graciously provided by Dr. Ivett Jelinek (NCI/NIH). All methods herein were reviewed and approved via NIAID Animal Study Proposal LAD 7E.

Bone Marrow Isolation and Culture. The method for eosinophil production from unselected bone marrow progenitors is described in detail in reference 8. Briefly, bone marrow cells were collected from the long bones by flushing with Iscove's Modified Dulbecco's Medium (Invitrogen), and red blood cells were lysed in $\mathrm{dH}_{2} \mathrm{O}$ followed by the addition of $10 \mathrm{X}$ PBS to $1 \mathrm{X}$ final concentration. After centrifugation, the cells were washed once in PBS containing $0.1 \%$ bovine serum albumin (BSA). 
The bone marrow cells were seeded at $10^{7} / \mathrm{mL}$ in media containing RPMI 1640 (Invitrogen) with 20\% fetal bovine (Cambrex), $100 \mathrm{IU} / \mathrm{mL}$ penicillin and $10 \mu \mathrm{g} / \mathrm{mL}$ streptomycin (Cellgro), $2 \mathrm{mM}$ glutamine (Invitrogen), 25 $\mathrm{mM}$ HEPES and $1 \mathrm{x}$ non-essential amino acids and $1 \mathrm{mM}$ sodium pyruvate (Gibco) and $50 \mu \mathrm{M} \beta$-mercaptoethanol (Sigma) and supplemented with $100 \mathrm{ng} / \mathrm{mL}$ stem-cell factor (SCF; PeproTech) and $100 \mathrm{ng} / \mathrm{mL}$ FLT3-Ligand (FLT3-L; PeproTech) from day 0 to day 4 . On day 4 , the media containing SCF and FLT3-L was replaced with media containing $10 \mathrm{ng} / \mathrm{mL}$ recombinant mouse interleukin-5 (rmIL-5; R\&D Systems) alone. Viable (trypan blueexcluding) cells were enumerated manually via hemocytometer counts and determined on triplicate wells.

Flow Cytometric Detection of Eosinophils. Cells were incubated with either PE-conjugated rat anti-mouse Siglec F or PE-conjugated IgG2A6 isotype control $\left(1 \mu \mathrm{g}\right.$ per $10^{6}$ cells; $\mathrm{BD}$ Pharmingen) for 30 minutes at $4{ }^{\circ} \mathrm{C}$. After staining, the cells were fixed in 4\% paraformaldehyde and analyzed by flow cytometry. Data were acquired with a FACSCalibur flow cytometer (BD Biosciences) and analyzed with FloJo software v 7.1 (Tree Star, Inc). Siglec F-positive cells were identified by comparison to the PE-conjugated IgG2A6 isotype control.

Degranulation Assay: Detection of eosinophil peroxidase (EPO) released by platelet-activating factor (PAF)-stimulated bmEos was essentially as described [15]. Cells were collected by centrifugation and resuspended phenol-red-free Roswell Park Memorial Institute (RPMI) medium at a concentration 250,000 cells $/ \mathrm{mL}$ and $25,000 / 100$ $\mathrm{uL}$ were used per well. One uL of platelet activating factor (PAF C16) or $1 \mathrm{uL}$ of vehicle, dimethyl sulfoxide (DMSO), was added to appropriate wells to achieve the indicated concentrations. Cells were incubated at $37^{\circ} \mathrm{C}, 5 \% \mathrm{CO}_{2}$ for 30 minutes. The assay was developed using $100 \mathrm{uL}$ ophenylene-diamine (OPD) reagent $(800 \mathrm{uL} 5 \mathrm{mM}$ OPD in 4 $\mathrm{mL} 1 \mathrm{M}$ Tris ( $\mathrm{pH} 8.0$ ), $5.2 \mathrm{~mL} \mathrm{H}_{2} \mathrm{O}$ and $1.25 \mathrm{uL} 30 \% \mathrm{H}_{2} \mathrm{O}_{2}$ ) in the presence of $\mathrm{H}_{2} \mathrm{O}_{2}$. The reaction was terminated by the addition of $100 \mu \mathrm{L}$ of $4 \mathrm{M} \mathrm{H}_{2} \mathrm{SO}_{4}$ to each well. The relative production of EPO was determined by reading the plate at
A.

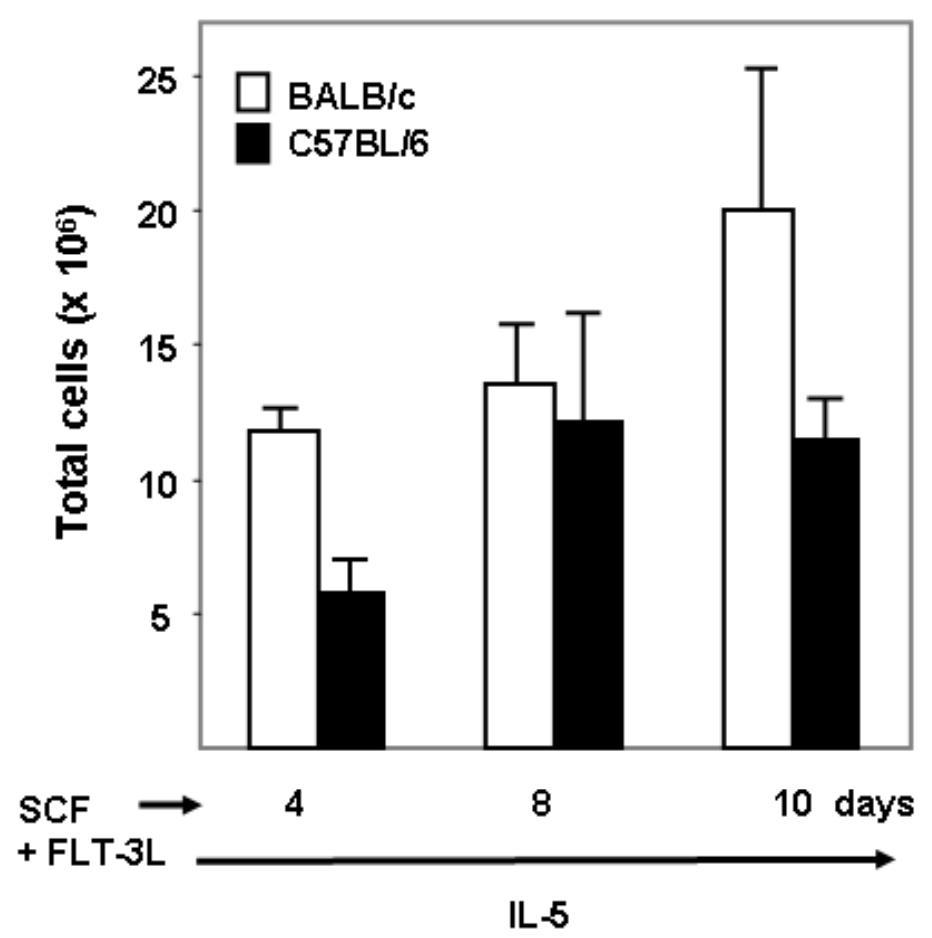

B.

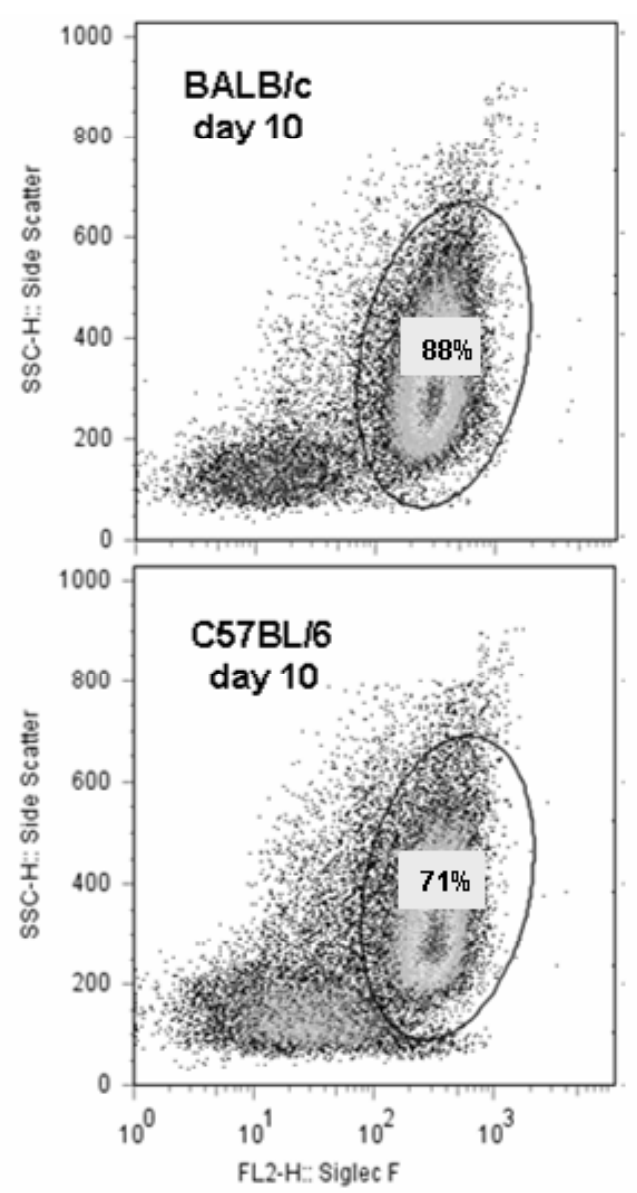

Fig. (1). Eosinophils generated in cultures of unselected bone marrow from both BALB/c and C57BL/6 mice. (A) Bone marrow cultures were initiated at $10^{7}$ cells $/ \mathrm{mL}$. The number of viable cells was determined at timepoints shown in response to rmSCF (100 ng / $\left.\mathrm{mL}\right)$ and rmFLT-3L (100 ng / mL) for 4 days after isolation, followed by rmIL-5 (10 ng / mL) alone thereafter. (B) Eosinophils were identified at day 10 in culture by side scatter (SSC, y-axis) and reactivity with anti-Siglec F+ antibodies (x-axis). 
wavelength $492 \mathrm{~nm}$. Data is reported as mean absorbance +/standard error of the mean in relation to vehicle only control (1\% DMSO).

\section{RESULTS}

Eosinophils (bmEos) are Generated from C57BL/6 Bone Marrow Culture. Our previous study examined production of functional eosinophils at high purity from unselected bone marrow from BALB/c mice [8]. Here we demonstrate production of bmEos from progenitors from C57BL/6 mice. Using the identical culture conditions (100 $\mathrm{ng} / \mathrm{mL} \mathrm{SCF}+100 \mathrm{ng} / \mathrm{mL}$ FLT-3L for 4 days, followed by $10 \mathrm{ng} / \mathrm{mL}$ IL-5 alone thereafter), $71 \%$ of the cells in C57BL/6 bone marrow culture at day 10 were Siglec F+ bmEos, comparable to the $88 \%$ bmEos detected in the $\mathrm{BALB} / \mathrm{c}$ bone marrow cultures (Fig. 1). Both BALB/c and C57BL/6 bone marrow cultures reach $\sim 100 \%$ bmEos by day 14 [8]. BmEos can also be generated from the $129 \mathrm{~Sv}$ mouse strain (data not shown).

BmEos from Gene-Deleted Progenitors. The percent bmEos were determined from cultures of C57BL/6 wild-type bone marrow and bone marrow isolated from TLR genedeleted mice (Fig. 2). As shown, individual deletions of TLR 2, TLR3, TLR 7 and TLR9 have no impact on the rate at or extent to which bmEos are generated in culture. All cultures reached virtually $100 \%$ bmEos at days $16-18$, including those from C57BL/6 wild-type mice.

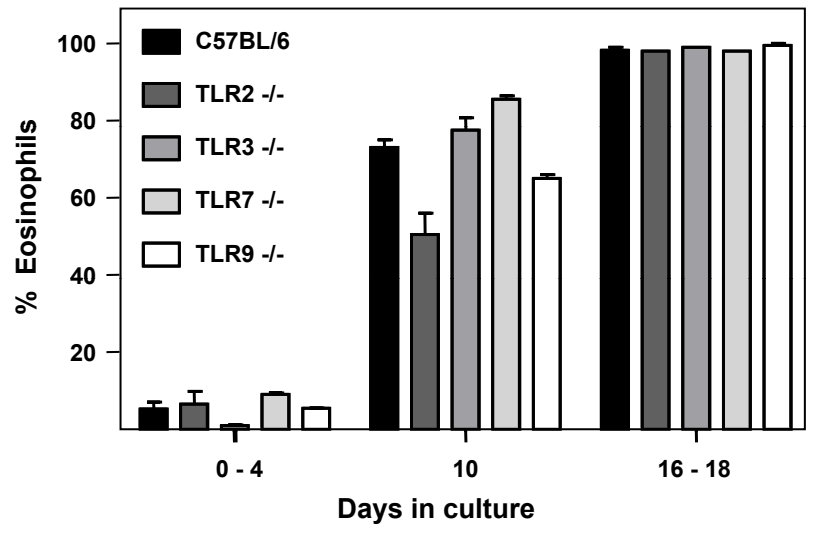

Fig. (2). Eosinophils generated from bone marrow of TLR 2, TLR 3, TLR 7, and TLR 9 gene-deleted mice. Eosinophils were identified by staining with Diff-Quik and are shown as percent of total cell number on days indicated.

BmEos Degranulate. In our previous publication [8], we found that bmEos expressed typical proteins and transcripts, and underwent chemotaxis in response to gradients of mouse eotaxin-1 (CCL11). Here, we characterize another functional response, as we demonstrate that mouse bmEos degranulate in a dose-dependent fashion in response to the eosinophilsecretagogue, platelet-activating factor (Fig. (3) PAF; [16, 17]).

BmEos from Eosinophil-Deficient $\triangle$ dbIGATA Mice. Interestingly, and in contrast to our previous study [9], with this cytokine regimen, markedly fewer bmEos were detected in bone marrow cultures from eosinophil-deficient $\triangle$ dblGATA mice when compared to those generated from BALB/c wild-type mice (Fig. 4).

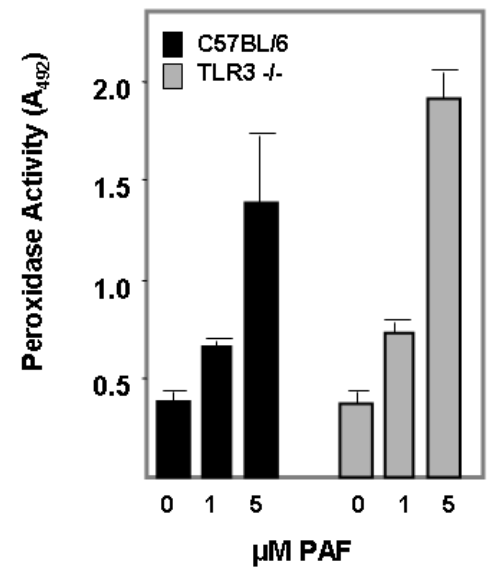

Fig. (3). Eosinophils generated from bone marrow of wild-type and TLR3 gene-deleted mice release eosinophil peroxidase in response to challenge with PAF. Extracellular peroxidase activity was measured as hydrolysis of o-phenylene diamine (OPD) as described [15]; peroxidase activity detected at baseline (zero concentration) represents the response to $1 \%$ DMSO vehicle control.

\section{DISCUSSION}

In this manuscript, we demonstrate the general nature of our bone marrow eosinophil culture protocol. Specifically, we document production of bmEos from $\mathrm{C} 57 \mathrm{BL} / 6$, a genetically-distinct wild-type strain used extensively for creating gene-deleted mice. We also generated bmEos from four independent gene-deleted mouse strains on the C57BL/6 background. The ability to generate bmEos from gene-deleted strains is a critical feature of this method, as mature eosinophils isolated from mouse blood and spleen are biosynthetically inert and have relatively little mRNA; as such, introduction of RNA-silencing agents are unlikely to have a substantial impact on protein targets. Specifically, we generated substantial numbers of TLR2, TLR3, TLR7 and TLR9 gene-deleted eosinophils that can be used for functional studies. Numerous TLRs have been detected in both human and mouse eosinophils [18-21]; TLR2 has been implicated in interactions of eosinophils with mycobacteria [19], and TLR7 was shown to be crucial for eosinophilmediated clearance of respiratory viruses in vivo [21]. There is also substantial evidence supporting a role for TLRs in hematopoeisis [22]; TLRs are expressed on pluripotent progenitors and they direct differentiation toward the myeloid (granulocyte, macrophage) lineages [23, 24].

We also revisited our findings on the role of the dblGATA enhancer of the mouse GATA-1 gene in promoting eosinophil hematopoiesis ex vivo. $\Delta$ dblGATA gene-deleted mice are completely devoid of mature eosinophils, both at baseline or in response to Th2 stimulation $[10,25,26]$; the molecular basis for this finding is not yet clear. In an earlier study, we found that $\triangle$ dblGATA and wild-type BALB/c mouse bone marrow cultures each yielded $\sim 5-7 \%$ eosinophils in response to four days with SCF and FLT-3L, followed by various combinations of IL-5, IL-3 and GM-CSF [9]. In this work, when we restrict the secondary stimulus to IL-5 alone, wild-type cultures undergo specific expansion of the eosinophil lineage, with bmEos representing nearly $100 \%$ of the cell population by day 14 . 
A.

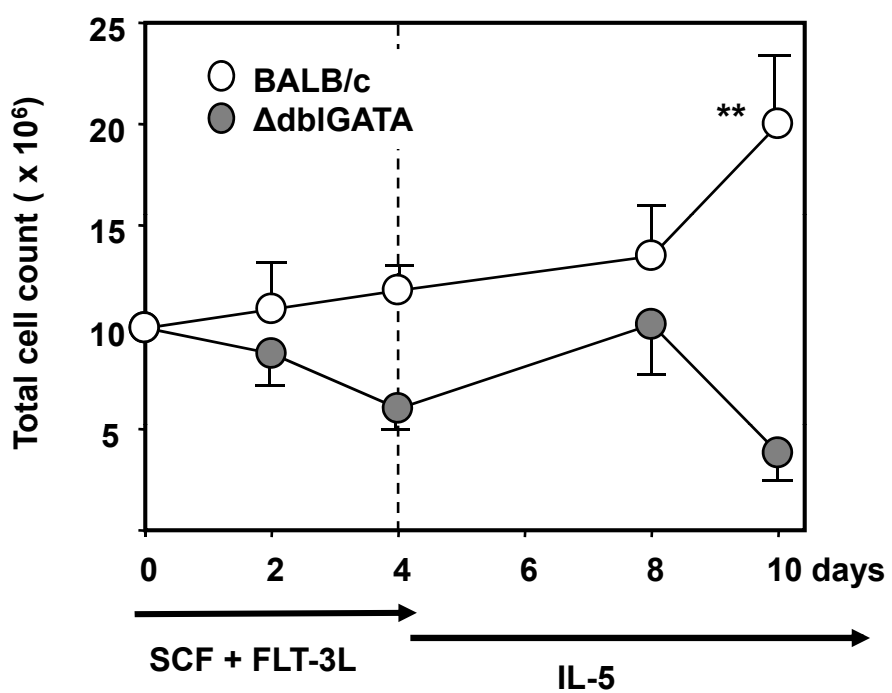

B.

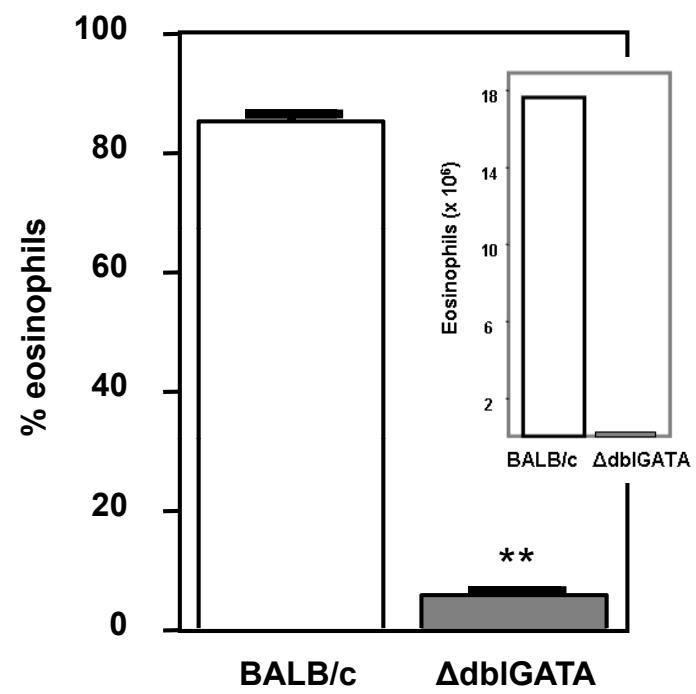

Fig. (4). Eosinophils generated from bone marrow of $\Delta$ dbIGATA eosinophil-deficient mice. (A) Bone marrow cultures were initiated at $10^{7}$ cells $/ \mathrm{mL}$. The number of viable cells was determined at timepoints shown in response to the cytokine regimen described in the Legend to Fig. (1). Significant difference between counts detected at day $10, * * p<0.01$. (B) Eosinophils identified by side scatter and Siglec $\mathrm{F}$ expression are shown as percent total cell number on day $10,{ }^{*} \mathrm{p}<0.01$. Inset: number of eosinophils in bone marrow culture at day 10 as calculated from the data in (A) and (B).

Interestingly, the $\triangle$ dblGATA bone marrow cultures can still generate eosinophils using IL-5 alone as the secondary stimulus, but the bmEo-population remains at $\sim 5 \%$ of the total, representing $\sim 80$-fold fewer bmEos than that produced by the parallel wild-type culture. Interestingly, the original cytokine combination, which included IL-5, IL-3 and GMCSF, skewed the distribution of GATA-1 transcripts, suggesting that the dblGATA deletion might be circumvented ex vivo by use of an alternative promoter [9]; we have not evaluated transcript distribution in response to IL-5 alone. However, we have shown clearly that the $\triangle$ dblGATA bone marrow progenitors are not capable of a complete response to IL-5. As such, this system can serve as an important tool for evaluating the molecular basis of the dblGATA deletion and its direct connection to IL-5mediated expansion of the eosinophil lineage.

\section{CONCLUSION}

In summary, we have shown that generation of eosinophils at high purity from unselected bone marrow progenitors proceeds effectively in a variety of wild-type and gene-deleted strains, and as such is a universal tool for the study of eosinophil structure and function.

\section{ACKNOWLEDGEMENTS}

The authors thank Dr. Rachel Caspi (NEI/NIH) for facilitating the transfer of TLR 2 -/- and TLR 9 -/- genedeleted mice, Dr. Jennifer Wang (University of Massachusetts Medical) for the TLR7 -/- mice (strains used with permission from Dr. S. Akira), and Dr. Ivett Jelinek (NCI, NIH) for providing TLR 3 -/- mice. We also thank Dr. Alison Humbles and Dr. Craig Gerard (Harvard Medical School) for the original male mice used to set up our
$\Delta$ dblGATA colony. This study was funded by NIAID Division of Intramural Research.

\section{REFERENCES}

[1] Rothenberg ME, Hogan SP. The Eosinophil. Annu Rev Immunol 2006; 24: 147-74.

[2] Hogan SP, Rosenberg HF, Moqbel R, et al. Eosinophils: biological properties and role in health and disease. Clin Exp Allergy 2008; 38: 709-50.

[3] Klion AD, Nutman TB. The role of eosinophils in host defense against helminth parasites. J Allergy Clin Immunol 2004; 113: 307.

[4] Fabre V, Beiting DP, Bliss SK, et al. Eosinophil deficiency compromises parasite survival in chronic nematode infection. $\mathrm{J}$ Immunol 2009; 182: 1577-83.

[5] Leckie MJ, ten Brinke A, Khan J, et al. Effects of an interleukin-5 blocking monoclonal antibody on eosinophils, airway hyperresponsiveness, and the late asthmatic response. Lancet 2000; 356: 2144-8.

[6] Nair P, Pizzichini MM, Kjarsgaard M, et al. Mepolizumab for prednisone-dependent asthma with sputum eosinophilia. N Engl J Med 2009; 360: 985-93.

[7] Haldar P, Brightling CE, Hargadon B, et al. Mepolizumab and exacerbations of refractory eosinophilic asthma. N Engl J Med 2009; 360: 973-84

[8] Dyer KD, Moser JM, Czapiga M, Siegel SJ, Percopo CM, Rosenberg HF. Functionally competent eosinophils differentiated ex vivo in high purity from normal mouse bone marrow. J Immunol 2008; 181: 4004-9.

[9] Dyer KD, Czapiga M, Foster B, et al. Eosinophils from lineageablated Delta dblGATA bone marrow progenitors: the dblGATA enhancer in the promoter of GATA-1 is not essential for differentiation ex vivo. J Immunol 2007; 179: 1693-9.

[10] Yu C, Cantor AB, Yang $\mathrm{H}$, et al. Targeted deletion of a highaffinity GATA-binding site in the GATA-1 promoter leads to selective loss of the eosinophil lineage in vivo. J Exp Med 2002; 195: 1387-95.

[11] Takeuchi O, Hoshino K, Kawai T, et al. Differential roles of TLR2 and TLR4 in recognition of gram-negative and gram-positive bacterial cell wall components. Immunity 1999; 11: 443-51. 
[12] Hemmi H, Kaisho $\mathrm{T}$, Takeuchi O, et al. Small anti-viral compounds activate immune cells via the TLR7 MyD88-dependent signaling pathway. Nat Immunol 2002; 3: 196-200.

[13] Hemmi H, Takeuchi O, Kawai T, et al. A Toll-like receptor recognizes bacterial DNA. Nature 2000; 408: 740-5

[14] Alexopoulou L, Holt AC, Medzhitov R, Flavell RA. Recognition of double-stranded RNA and activation of NF-kappaB by Toll-like receptor 3. Nature 2001; 413: 732-8.

[15] Adamko DJ, Wu Y, Gleich GJ, Lacy P, Moqbel R. The induction of eosinophil peroxidase release: improved methods of measurement and stimulation. J Immunol Methods 2004; 291: 1018.

[16] Simon HU, Weber M, Becker E, Zilberman Y, Blaser K, LeviSchaffer F. Eosinophils maintain their capacity to signal and release eosinophil cationic protein upon repetitive stimulation with the same agonist. J Immunol 2000; 165: 4069-75.

[17] Bartemes KR, McKinney S, Gleich GJ, Kita H. Endogenous platelet-activating factor is critically involved in effector functions of eosinophils stimulated with IL-5 or IgG. J Immunol 1999; 162: 2982-9.

[18] Nagase H, Okugawa S, Ota Y, et al. Expression and function of Toll-like receptors in eosinophils: activation by Toll-like receptor 7 ligand. J Immunol 2003; 171: 3977-86.
[19] Driss V, Legrand F, Hermann E, et al. TLR2-dependent eosinophil interactions with mycobacteria: role of alpha-defensins. Blood 2009; 113: 3235-44.

[20] Mansson A, Cardell LO. Role of atopic status in TLR7 and TLR9mediated activation of human eosinophils. J Leukoc Biol 2009; 85 : 719-27.

[21] Phipps S, Lam CE, Mahalingam S, et al. Eosinophils contribute to innate antiviral immunity and promote clearance of respiratory syncytial virus. Blood 110: 1578-86.

[22] McGettrick AF, O'Neill LAJ. Toll-like receptors: key activators of leucocytes and regulator of haematopoiesis. Br J Haematol 2007 139: $185-93$

[23] Nagai Y, Garrett KP, Ohta S, et al. Toll-like receptors on hematopoietic progenitor cells stimulate innate immune system replenishment. Immunity 2006; 24: 801-12.

[24] Sioud M, Floisand Y, Forfang L, Lund-Johansen F. Signaling through toll-like receptor $7 / 8$ induces the differentiation of human bone marrow CD34+ progenitor cells along the myeloid lineage. J Mol Biol 2006; 364: 945-54.

[25] Humbles AA, Lloyd CM, McMillan SJ, et al. A critical role for eosinophils in allergic airways remodeling. Science 2004; 305 : 1776-9.

[26] Swartz JM, Dyer KD, Cheever AW, et al. Schistosoma mansoni infection in eosinophil lineage-ablated mice. Blood 2006; 108: $2420-7$.

(C) Dyer et al.; Licensee Bentham Open.

This is an open access article licensed under the terms of the Creative Commons Attribution Non-Commercial License (http://creativecommons.org/licenses/by$\mathrm{nc} / 3.0 /$ ) which permits unrestricted, non-commercial use, distribution and reproduction in any medium, provided the work is properly cited. 